\title{
Assessing the Renovation of Existing Residential Buildings Regarding Environmental Efficiency
}

\author{
Heng Zhang, Siu Lai Lei \\ Department of Architecture, \\ National Cheng Kung University, Taiwan \\ changlin@mail.ncku.edu.tw
}

\begin{abstract}
Renovation of buildings is a sustainable way to keep the built environment functional. Thus, it is important to find a way to assess the efficiency of a renovation activity. Besides functionality, which is the basic requirement for any building, sustainability has also become a significant factor due to the environmental challenges we face today. This study adopts principles of environmental efficiency in proposing an assessment framework for existing residential buildings that simultaneously reflects functionality and sustainability. A pilot study demonstrates the proposed framework provides useful information for prioritizing critical renovation issues, leading to notable improvements in functionality and sustainability.
\end{abstract}

Keywords: Environmental efficiency; functional quality; environmental loading; existing residential building

eISSN 2398-4295 @ 2018. The Authors. Published for AMER ABRA cE-Bs by e-International Publishing House, Ltd., UK. This is an open-access article under the CC BY-NC-ND license (http://creativecommons.org/licenses/bync-nd/4.0/). Peer-review under responsibility of AMER (Association of Malaysian Environment-Behaviour Researchers), ABRA (Association of Behavioural Researchers on Asians) and cE-Bs (Centre for EnvironmentBehaviour Studies), Faculty of Architecture, Planning \& Surveying, Universiti Teknologi MARA, Malaysia.

DOI: http://dx.doi.org/10.21834/ajbes.v3i9.60 


\subsection{Introduction}

Existing residential buildings warrant special attention in Taiwan due to their high ratio in the overall building stock. In Taiwan, the percentage of households living in buildings over 10 years old is over $90 \%$ (Construction and Planning Agency, 2008; Directorate General of Budget, 2000). Occupants living in older buildings, especially buildings over 35 years, are more likely to undertake a major renovation (Nair, Gustavsson, \& Mahapatra, 2010). The situation has been aggravated by rapid and intense change in the society in the past few decades, including aging of population, decline of birth rate, increase of leisure time, and new technology. Consequently, the functionality of existing residential buildings is becoming increasingly insufficient for meeting occupants' needs, with the kitchen, dining area, clothesdrying space being typically unsatisfactory (Salleh, 2008). Renovation is one of the most direct ways to eliminate functional deficiencies. In addition, the global environmental crisis has led to a significant rise in environmental consciousness. Sustainable design and highperformance buildings have thus gained increasing importance in the construction industry for buildings both new and old. According to Erlandsson and Lvein (Erlandsson \& Levin, 2005), renovation and maintenance of existing buildings can greatly improve environmental performance. Thus, sustainability is also a key consideration in residential renovation besides functionality.

To control and evaluate the effect of renovation, a reliable tool would be of great value, especially for stakeholders looking for guidance in prioritizing critical renovation issues within a constrained budget. A number of building environmental assessment tools have been developed within the specific context of local conditions in different countries (Forsberg \& Von Malmborg, 2004). But an appropriate assessment tool to simultaneously evaluate the functionality and environmental efficiency of existing residential buildings to be renovated is still missing. This study proposes a framework for assessing the functional environmental performance of existing residential buildings, with a focus on prioritizing renovation improvements.

\subsection{Literature Review}

Environmental efficiency is derived from eco-efficiency, which is defined by the World Business Council for Sustainable Development (WBSCD) as the product or service value divided by its influence on the environment (Verfaillie \& Bidwell, 2000). First presented in 1992, eco-efficiency has received considerable attention and has been widely applied at different levels in recent years (Li, Hui, Leung, Li, \& Xu, 2010). Many assessment tools have been developed following the concept of eco-efficiency. Assefa et al. (2007) proposed the EcoEffect framework for assessing the environmental efficiency of buildings, which is useful for existing buildings as well as buildings in design phase. When CASBEE (Comprehensive Assessment System for Building Environmental Efficiency) (Endo, Murakami, \& lkaga, 2008) was unveiled, building environmental efficiency (BEE) attracted broad attention in the architectural management sector. The BEE indicator is composed of two groups of indices: building environmental quality and building environmental load. Malmquist and Glaumann 
(2009) applied the concept of environmental efficiency to develop a framework for assessing user satisfaction with indoor environments and the environmental impact related to the energy use of residential buildings. These tools for accurately assessing a building's environmental efficiency are practical and useful for managing its environment and subsequent improvement (Assefa et al., 2007).

\subsection{Methodology}

In this study, an assessment framework is developed for the environmental efficiency of functionality $\left(E_{F}\right)$ based on two groups of indices: functional quality $(F Q)$ and environmental loading (EL). The fuzzy Delphi Method (FDM) was used to confirm the suitability of the indices, while the fuzzy Analytic Hierarchy Process (FAHP) was used to determine the weighting of each index.

\subsection{The functional quality indices (FQ)}

The functional quality indices include three levels. Level 1 consists of four categories: functional ability, durability and reliability, flexibility and adaptability, and the outdoor environment on the site and its surroundings (Chang, Chiang, \& Chou, 2006; JSBC, 2005; Lee \& Burnett, 2006). The suitability of the levels 2 and level 3 indices was then evaluated through the fuzzy Delphi Method. A survey was conducted to collect expert opinions about the importance of the indices. A total of twelve questionnaires were collected from experts, including five architects, three government officials and four scholars in architecture-related fields. The experts were asked to evaluate the importance of each index by offering minimum and maximum acceptable values on a scale of 0 (very unimportant) to 10 (very important). To express these values, we developed triangular fuzzy numbers for the minimum acceptable value (Mini) and maximum acceptable value (Maxi) of a given index (Kuo \& Chen, 2008). Each triangular fuzzy number consisted of three values derived from the expert opinions: the lowest value, the geometric mean and the ultimate value. A consensus was reached for two conditions: the two triangular fuzzy numbers either had no overlap or had an overlap that falls within the range of two geometric means (see Fig. 1). A threshold value of 6 was then set, based on one established in corresponding studies adopting the same 0-10 point scale (Hsu, Wey, \& Tsai, 2007). As shown in Table 1, all the consensus values for the level 2 indices are higher than the threshold value (i.e., 6). The results indicate the experts confirmed the suitability of these nine functional quality indices in level 2. In addition, for the 21 indices in level 3 , the consensus values for "comprehensive decoration planning" (5.70) in "amenity", and "flexibility in floor height" (5.57) in "flexibility" are lower than the threshold value, indicating these two indices may not be important in the functional quality evaluation for residential buildings. They were therefore eliminated. Fig. 2 depicts the index group of functional quality integrating the expert opinions. This assessment group is composed of four categories of indices. Nine indices in level 2 and 19 in level 3 are used as the assessment indices for evaluating the functional quality of residential buildings. 


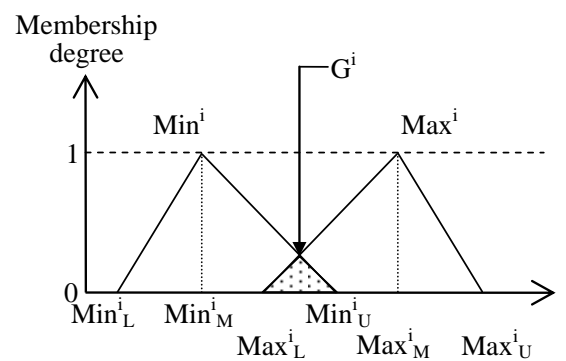

Experts' opinions

Note: $\mathrm{Min}^{\prime}{ }_{L}, \mathrm{Min}^{\mathrm{M}}$, and Mini $\cup$ refer to the lowest value, geometric mean and ultimate value of the minimum acceptable value, respectively. Max ${ }^{i}, M_{1}{ }^{i}{ }_{M}$, and Maxi refer to the lowest value, geometric mean and ultimate value of the maximum acceptable value, respectively. $G^{i}$ refers to the consensus value.

Fig. 1. Triangular fuzzy numbers with overlap



Fig. 2. Indices of functional quality (FQ) 
Table 1. Consensus values of components (level 2) for functional quality

\begin{tabular}{|c|c|c|c|c|c|c|c|}
\hline \multirow{2}{*}{ Component } & \multicolumn{3}{|c|}{$\begin{array}{l}\text { Minimum Acceptable } \\
\text { Value }\end{array}$} & \multicolumn{3}{|c|}{$\begin{array}{l}\text { Maximum Acceptable } \\
\text { Value }\end{array}$} & \multirow{2}{*}{$\begin{array}{l}\text { Consensus } \\
\text { Value }\end{array}$} \\
\hline & $\begin{array}{l}\mathrm{Mi} \\
\mathrm{ni}\end{array}$ & Min'm & $\begin{array}{l}\operatorname{Min} \\
u\end{array}$ & $\begin{array}{l}\mathrm{Ma} \\
\mathrm{X}_{\mathrm{L}}\end{array}$ & $\begin{array}{l}\text { Maxi } \\
M\end{array}$ & $\begin{array}{l}\text { Maxi } \\
u\end{array}$ & \\
\hline A1 Usability & 5 & 6.02 & 7 & 7 & 9.21 & 10 & 7.62 \\
\hline A2 Amenity & 4 & 5.48 & 7 & 7 & 9.12 & 10 & 7.30 \\
\hline B1 Service life & 3 & 4.74 & 6 & 7 & 8.79 & 10 & 6.76 \\
\hline B2 Reliability of equipment & 3 & 4.89 & 7 & 7 & 8.88 & 10 & 6.89 \\
\hline C1 Flexibility & 2 & 4.38 & 7 & 6 & 7.85 & 10 & 6.41 \\
\hline C2 Adaptability of equipment & 4 & 5.16 & 7 & 7 & 8.80 & 10 & 6.98 \\
\hline D1 Preservation \& creation of biotope & 5 & 4.87 & 7 & 7 & 8.84 & 10 & 6.85 \\
\hline D2 Townscape \& landscape & 4 & 4.17 & 6 & 7 & 7.94 & 10 & 6.06 \\
\hline $\begin{array}{l}\text { D3 Local characteristics \& outdoor } \\
\text { amenities }\end{array}$ & 3 & 4.20 & 6 & 7 & 7.95 & 9 & 6.08 \\
\hline
\end{tabular}

Note: Mini $_{L}, \mathrm{Min}^{i} \mathrm{M}$, and Mini ${ }_{u}$ refer to the lowest value, geometric mean and ultimate value of the minimum

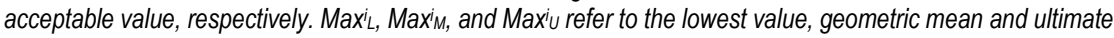
value of the maximum acceptable value, respectively.

\subsection{The environmental loading indices (EL)}

Level 1 of the environmental loading indices includes three categories: energy, resources and materials, and off-site environment (Chang et al., 2007; JSBC, 2005; Lee \& Burnett, 2006). The suitability of indices in level 2 was evaluated by FDM and the results are shown in Table 2. Note the consensus value of "operational efficiency" (5.89) is lower than the threshold value and is excluded in the assessment framework. The result implies that operational efficiency may not be important for assessing the environmental loading of residential buildings. Fig. 3 shows the index group of environmental loading integrating the expert opinions. This index group is composed of three categories and nine indices for evaluating the environmental loading of residential buildings.

Table 2. Consensus values of components (level 2) for environmental loading

\begin{tabular}{|c|c|c|c|c|c|c|c|}
\hline \multirow{2}{*}{ Component } & \multicolumn{3}{|c|}{$\begin{array}{l}\text { Minimum acceptable } \\
\text { value }\end{array}$} & \multicolumn{3}{|c|}{$\begin{array}{l}\text { Maximum acceptable } \\
\text { value }\end{array}$} & \multirow{2}{*}{$\begin{array}{l}\text { Consensus } \\
\text { Value }\end{array}$} \\
\hline & Min'L & Minim & Miniu & Maxi & Maxim & Maxiu & \\
\hline $\begin{array}{l}\text { E1 Reduction of building } \\
\text { thermal load }\end{array}$ & 3 & 5.71 & 8 & 7 & 9.03 & 10 & 7.47 \\
\hline E2 Natural energy utilization & 3 & 4.89 & 7 & 7 & 8.43 & 10 & 6.66 \\
\hline E3 Efficiency in service system & 4 & 5.52 & 7 & 7 & 8.61 & 10 & 7.07 \\
\hline E4 Efficiency operation & 3 & 4.16 & 6 & 5 & 7.64 & 10 & 5.59 \\
\hline F1 Water saving & 4 & 4.88 & 6 & 7 & 8.28 & 10 & 6.58 \\
\hline F2 Green materials utilization & 4 & 4.57 & 6 & 7 & 8.36 & 10 & 6.47 \\
\hline G1 Air pollution control & 3 & 5.06 & 7 & 5 & 7.88 & 10 & 6.20 \\
\hline $\begin{array}{l}\text { G2 Wind damage \& sunlight } \\
\text { obstruction }\end{array}$ & 3 & 4.91 & 7 & 7 & 8.30 & 10 & 6.61 \\
\hline $\begin{array}{l}\text { G3 Consideration of thermal } \\
\text { impact }\end{array}$ & 3 & 5.45 & 8 & 7 & 8.69 & 10 & 7.40 \\
\hline
\end{tabular}




\begin{tabular}{|l|l|l|l|l|l|l|l|}
\hline $\begin{array}{l}\text { G4 Consideration of local } \\
\text { infrastructure load }\end{array}$ & 3 & 5.04 & 7 & 7 & 8.36 & 10 & 6.70 \\
\hline
\end{tabular}

Note: Mini ${ }^{\prime}, \mathrm{Min}_{\mathrm{M}} \mathrm{M}$, and Miniu refer to the lowest value, geometric mean and ultimate value of the minimum acceptable value, respectively. Maxi ${ }^{\prime}, M^{\prime} x^{i} M$, and Maxi $u$ refer to the lowest value, geometric mean and ultimate value of the maximum acceptable value, respectively

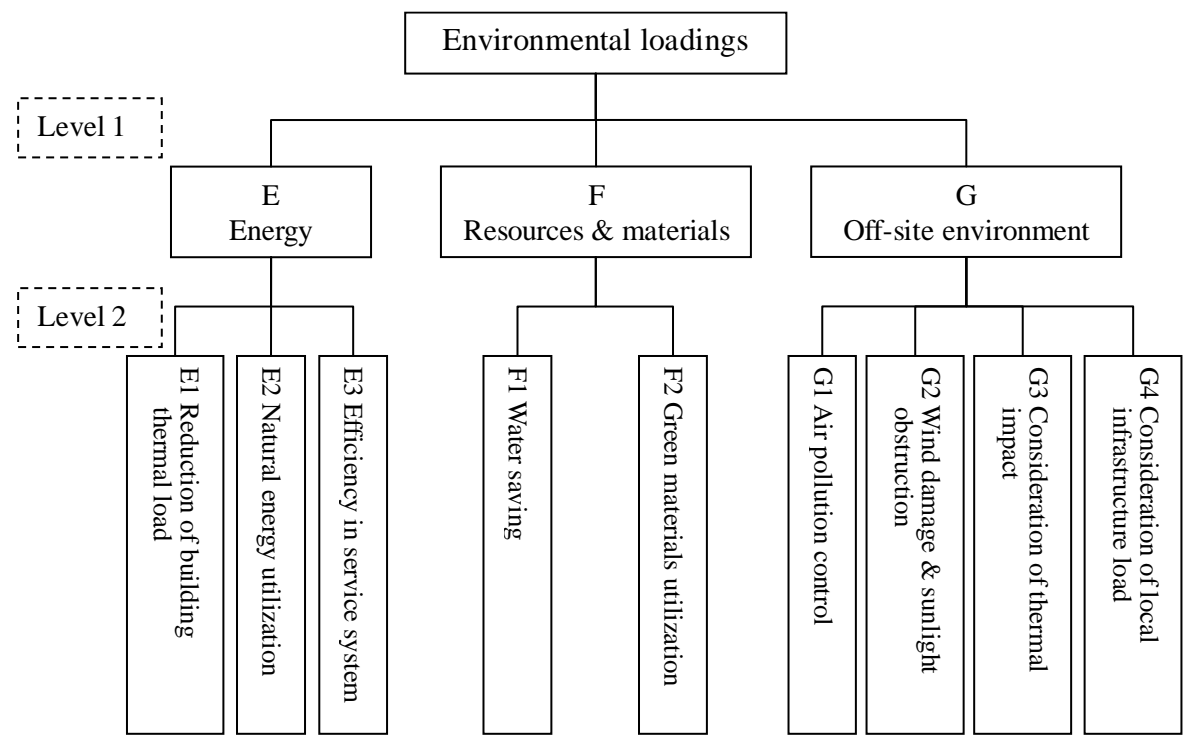

Fig. 3. Indices of environmental loading (EL)

\subsection{Weighting}

After setting the indices of the assessment framework, we used the fuzzy Analytic Hierarchy Process (FAHP) to determine the weighting of each index in the two groups of indices. Experts were asked to compare the indices in pairs to prioritize the relative importance of them in each index group. A triangular fuzzy number, with scores from 1 to 9 , was used to represent the evaluation of the paired comparison. The triangular fuzzy number is composed of three values, namely the minimum acceptable value, most-likely value and maximum acceptable value (Pan, 2008). The opinion of each expert was tested, and the consistency ratio is deemed acceptable if it falls below 0.1 (Kwong \& Bai, 2003). The similarity aggregation method (SAM) was then used to integrate the fuzzy expert opinions and evaluate the component weighting in each group of indices (Hsu, Lee, \& Kreng, 2010; Wang \& Tseng, 2003).

Fourteen expert questionnaires were collected, and two with consistency ratio greater than 0.1 were discarded, leaving a total of 12 valid responses retained for analysis. The expert group included four architects, four government officials and four scholars in architecture-related fields. The index weighting for functional quality was calculated. The 
results indicate the weighting of "functional ability" $(0.52)$ was significantly higher than that of the other three categories: 0.14 for "durability and reliability", 0.15 for "flexibility and adaptability", and 0.19 for "outdoor environment"(see Fig. 4). In the index group of environmental loading, the weighting of "energy" (0.52) was considerably higher than the other two categories: 0.21 for "resources and materials" and 0.27 for "off-site environment". (see Fig. 5).

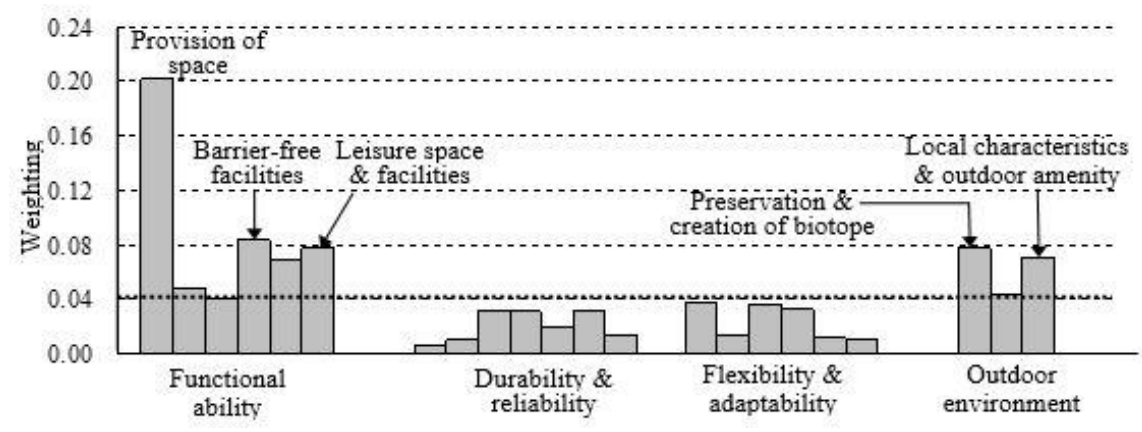

Fig. 4. Weighting of assessment items for functional quality

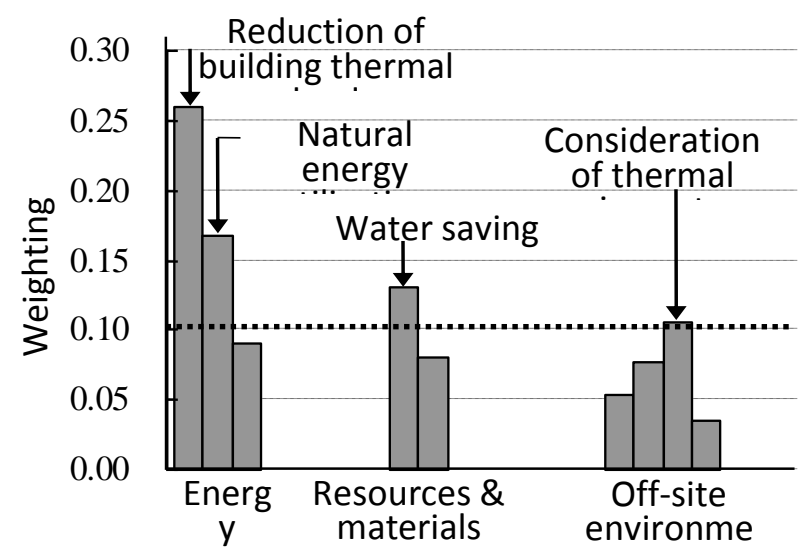

Fig. 5. Weighting of assessment items for environmental loading

\subsection{Pilot test}

This section describes the application of the environmental efficiency of functionality on existing residential buildings using an actual building in southern Taiwan. The building (see Fig. 6) was chosen for the pilot test because it is a very typical mixed-use building for Taiwan. Completed in 1994, it is an eight-story block building with 60 flats and 12 commercial units on ground floor and a total floor area of $6740 \mathrm{~m}^{2}$. 
To evaluate the environmental efficiency of functionality of the building, scores were given to assessment items for both the functional quality and environmental loading of the building. They were three levels of score: one point for poor, two for adequate, and three for excellent. The scores were then multiplied by their corresponding weighting. The scores for functional quality $\left(\mathrm{S}_{\mathrm{FQ}}\right)$ and reduction of environmental loading $\left(\mathrm{S}_{\mathrm{LR}}\right)$ could then be calculated by adding together the scores of all items in the respective group of indices. Finally, as shown in Formula (1), environmental efficiency of functionality $\left(E_{F}\right)$ was calculated as functional quality ( $F Q$ ) divided by environmental loading (EL). $F Q$ is defined as the score of functional quality $\left(\mathrm{S}_{\mathrm{FQ}}\right)$, and $E \mathrm{E}$ is defined as the conversion of the environmental loading reduction score (SLR) into environmental loading score ( $\left.\mathrm{S}_{\mathrm{EL}}\right)$, as shown below. The range for both $\mathrm{S}_{\mathrm{FQ}}$ and $S_{E L}$ was 1.00 3.00, and the range for $E_{F}$ was 3.00 0.33. A higher value of $E_{F}$ represents better environmental performance.

$$
E E_{F}=F Q / E L=S_{F Q} / S_{E L}=S_{F Q} /\left(4-S_{L R}\right)
$$

The results of the environmental efficiency of functionality assessment for the pilot test are presented below. Fig. 7 shows the score for each category in the assessment framework. Note, except for the score of functional ability (2.20), which exceeded the basic level, the score of all the other categories were below 2.00; scores for outdoor environment (1.00) and reduction of impact on off-site environment (1.00) were especially low. The total scores for functional quality and reduction of environmental loading were 1.76 and 1.39 , respectively. The latter was then converted to an environmental loading score with a resulting value of 2.61. Finally, the environmental efficiency of functionality of the pilot test was calculated using Formula (1) with a resulting value of 0.68 .

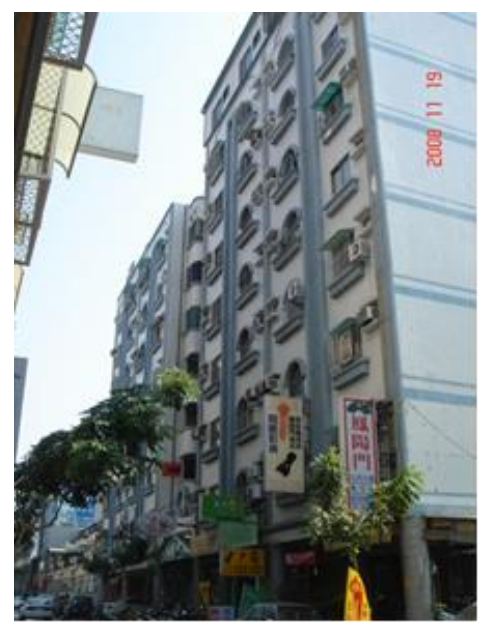

Fig. 6. Facade of the test building assessment framework

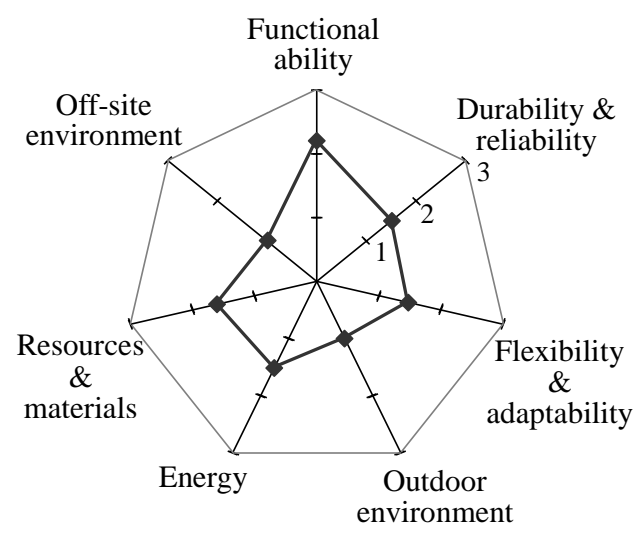

Legend: $\diamond$ Score level

Fig.; 7. Score of categories in the 
Figures 8 and 9 show, respectively, the performance scores for indices in functional ability and environmental loading. To highlight items critical to improving renovation performance, the performance, weighting and performance score of each indices are displayed in the figures. The performance score was calculated by multiplying the performance of the assessment item by its weighting. As shown in Fig. 8, items with lower performance (i.e. under $67 \%$ ) and higher weighting (i.e. above 0.04 ) for functional quality, such as "provision of storage", "barrier-free facilities", "preservation and creation of biotope", and "local characteristics and outdoor amenity" were recommended as renovation priorities. Similarly, Fig. 9 suggests renovation priorities for reducing environmental loading include "natural energy utilization" and "consideration of thermal impact on off-site environment", which exhibit lower performance (i.e. below $67 \%$ ) and higher weighting (i.e. above 0.10 )..

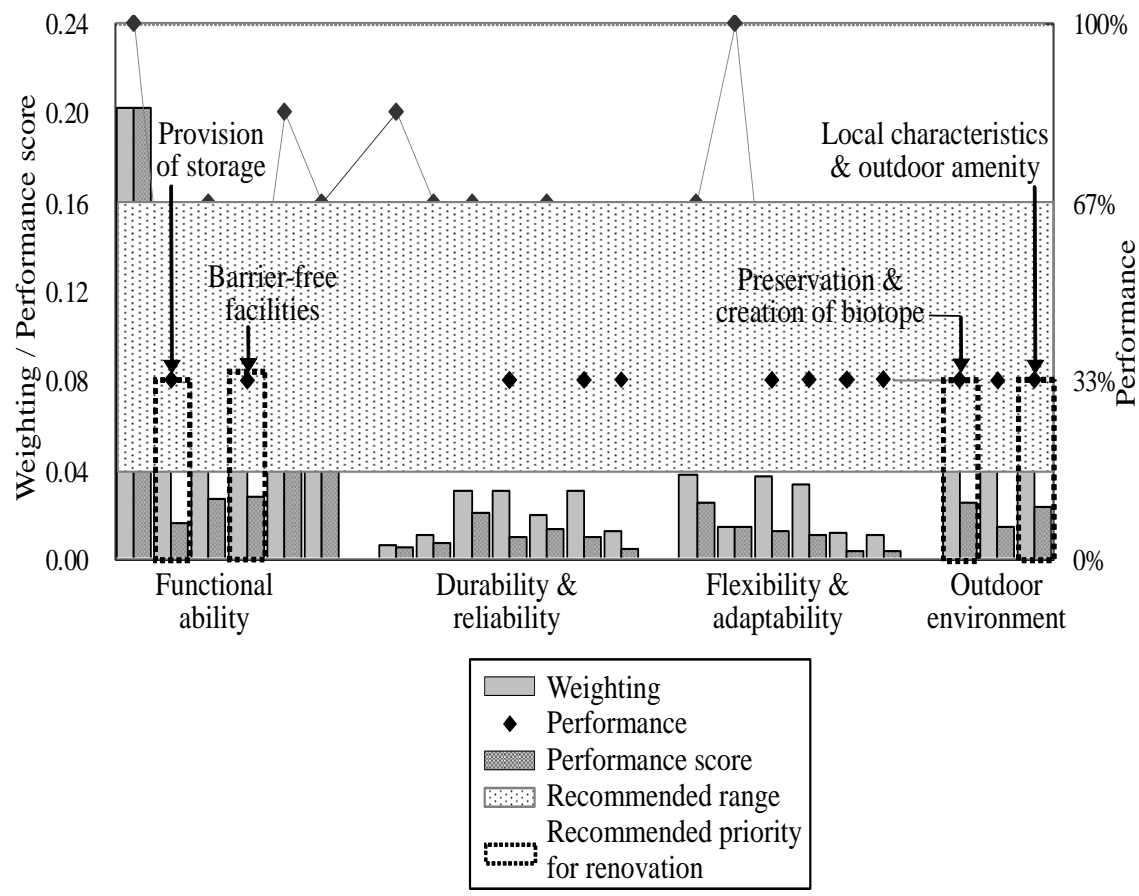

Note: The upper limit of the recommended range of renovation is the basic performance (67\%) and the lower limit is the highest index weighting.

Fig. 8. Performance score of assessment items for functional quality 

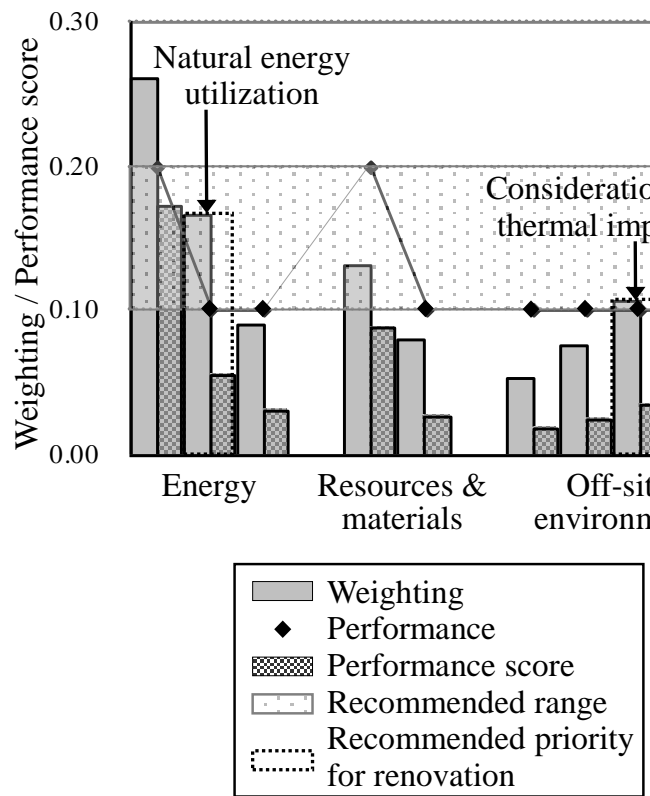

$100 \%$

$67 \%$

37\% छ

$0 \%$

$\begin{array}{ccc}\text { Energy } & \begin{array}{c}\text { Resources \& } \\ \text { materials }\end{array} & \begin{array}{c}\text { Off-site } \\ \text { environment }\end{array}\end{array}$

Weighting

- Performance

Performance score

Recommended range

for renovation

Note: The upper limit of the recommended range for renovation is the basic performance $(67 \%)$ and the lower limit is the highest index weighting.

Fig. 9. Performance scores of assessment items for environmental loading

\subsection{Discussion}

In the study, the index weighting for evaluating the functional quality and environmental loading of residential buildings were determined by expert opinions. The results (see Fig. 4) show, aside from the fundamental necessity of "provision of space", the important indices are often related to social issues, such as population aging, quality of life, and biodiversity. Social and environmental issues, which have received considerable attention recently, also figure prominently in expert opinions with respect to the functional quality. Developing assessment tools based on these components may encourage architects or project managers to pay more attention to the design of fundamental functions, as well as barrier-free facilities, leisure space and facilities, and environmental preservation. Furthermore, the results suggest "energy" is an important issue for reducing environmental loading. "Reduction of building thermal load", "natural energy utilization", "water saving" and "consideration of thermal impact" have higher weighting (see Fig. 5), indicating that resolving thermal issues and saving energy through appropriate design and management strategies may contribute to efficient reduction of environmental loading for residential buildings.

In the pilot test, the value of $\mathrm{EE}_{\mathrm{F}}(0.68)$ indicates the test building performs poorly in environmental efficiency of functionality $\left(\mathrm{EE}_{\mathrm{F}}\right)$. The test building is found to have inadequate 
consideration for biodiversity, landscape quality, and local characteristics in the design and management of the outdoor environment. The results reflect oversight in the design and management of the project with regards to quality of the outdoor environment and impact on the off-site environment. From the standpoint of well-being for humans and the ecosystem, the outdoor environment is an important issue in the improvement of building properties (Assefa, Glaumann, Malmqvist, \& Eriksson, 2010). Architects or condo management committees should consider the design and management of the outdoor environment with respect to functional quality and environmental loading.

\subsection{Conclusion}

In response to the dissatisfaction of many homeowners with the functional quality of their homes and their desire to renovate, we have developed a framework for evaluating the environmental efficiency of functionality for existing residential buildings. Based on expert opinions, the most critical issues for environmental efficiency of functionality in residential buildings are "functional ability", "outdoor environment", and "energy". In addition, the evaluation of the environmental efficiency of functionality through a pilot test shows the proposed framework can provide valuable information to homeowners in identifying highpriority or critical issues for improving functional quality as well as reducing the environmental loading when carrying out renovations.

\section{Acknowledgement}

This study was supported by a grant from the National Science Council, Taiwan, Republic of China, under the project NSC96-2621-Z006-003.

\section{References}

Assefa, G., Glaumann, M., Malmqvist, T., \& Eriksson, O. (2010). Quality versus impact: Comparing the environmental efficiency of building properties using the EcoEffect tool. Building and Environment, 45(5), 1095-1103.

Chang, K.-F., Chiang, C.-M., \& Chou, P.-C. (2007). Adapting aspects of GBTool 2005-searching for suitability in Taiwan. Building and Environment, 42(1), 310-316.

Construction and Planning Agency. (2008). Occupancy permits in Taiwan and Fuchien Area - By use. Taipei: Ministry of Interior.

Endo, J., Murakami, S., \& lkaga, T. (2008). Designing a system to apply an assessment method of buildings for all lifecycle stages based on the concept of eco-efficiency. Journal of ASTM International, 5(2), 1-11.

Erlandsson, M., \& Levin, P. (2005). Environmental assessment of rebuilding and possible performance improvements effect on a national scale. Building and Environment, 40, 1459-1471. 
Forsberg, A., \& Von Malmborg, F. (2004). Tools for environmental assessment of the built environment. Building and Environment, 39, 223-228.

Hsu, H.-M., Wey, W.-M., \& Tsai, P.-J. (2007). The applications of Analytic Network Process to the priorities of interdependent housing projects selection. Journal of Architecture, 63, 49-74.

Hsu, Y.-L., Lee, C.-H., \& Kreng, V. B. (2010). The application of Fuzzy Delphi Method and Fuzzy AHP in lubricant regenerative technology selection. Expert Systems with Applications, 37(1), 419-425.

Kuo, Y.-F., \& Chen, P.-C. (2008). Constructing performance appraisal indicators for mobility of the service industries using Fuzzy Delphi Method. Expert Systems with Applications, 35(4), 1930-1939.

Kwong, C. K., \& Bai, H. (2003). Determining the Importance Weights for the Customer Requirements in QFD Using a Fuzzy AHP with an Extent Analysis Approach. IIE Transactions, 35(7), 619-626.

Li, D. Z., Hui, E. C. M., Leung, B. Y. P., Li, Q. M., \& Xu, X. (2010). A methodology for eco-efficiency evaluation of residential development at city level. Building and Environment, 45(3), 566-573.

Nair, G., Gustavsson, L., \& Mahapatra, K. (2010). Factors influencing energy efficiency investments in existing Swedish residential buildings. Energy Policy, 38(6), 2956-2963.

Pan, N.-F. (2008). Fuzzy AHP approach for selecting the suitable bridge construction method. Automation in Construction, 17(8), 958-965.

Salleh, A. G. (2008). Neighbourhood factors in private low-cost housing in Malaysia. Habitat International, 32, 485493.

Verfaillie, H. A., \& Bidwell, R. (2000). Measuring Eco-Efficiency: A guide to reporting company performance. Genava: World Business Council for Sustainable Development. 